\title{
UNIVERSIDADE E TRABALHO: A FUNÇÃO SOCIAL DA EDUCAÇÃO FRENTE AO MUNDO DO TRABALHO ${ }^{1}$
}

\author{
Ronaldo Marcos de Lima ARAUJO ${ }^{2}$ \\ PPGED/Instituto de Ciências da Educação/UFPA \\ rlima@ufpa.br
}

Resumo: Recuperamos o conceito de trabalho como atividade vital por meio da qual o homem satisfaz as suas necessidades, produz a cultura e as instituições como o Estado, resgatamos várias teses sobre a relação entre a esfera do trabalho e a esfera da educação e, a partir da compreensão de que a função do trabalho e da educação é produzir a humanização, problematizamos as formas como o trabalho vem se realizando na Amazônia brasileira, marcado por um uso predatório da força de trabalho e do meio ambiente. Por fim, tecemos algumas considerações sobre a necessidade de a educação em geral e a universidade, em particular, estarem articuladas a um projeto social de valorização do trabalho e de preservação das riquezas materiais e imateriais da Amazônia.

Palavras-chave: Universidade. Trabalho. Amazônia.

Abstract: We recoup the work concept as vital activity by means of which the man satisfies its necessities, produces the culture and institutions as the State, we rescue some theses on the relation between the work sphere and education sphere and, from the understanding that the function of the work and the education is to produce the humanizing, we problematized the manners as the work is being done at Brazilian Amazônia, marked for a predatory use of the work force and of the environment. Finally we raised some considerations about the necessity of the education in general and of the university, particularly, articulated with a social project of valuation of the work and preservation of the material and incorporeal wealth of Amazônia.

Keywords: University. Work. Amazon.

\footnotetext{
${ }^{1}$ Artigo originalmente construído sob encomenda da Universidade Federal da Integração Amazônica - UNIAM.

${ }^{2}$ Professor do Instituto de Ciências da Educação da UFPA. Pesquisador do CNPq. Coordenador do Grupo de Estudos e Pesquisas sobre Trabalho e Educação da UFPA. rlima@ufpa.br.
} 


\section{Introdução}

\section{O trabalho e a sua nova configuração no mundo contemporâneo}

Braverman (1974) identifica o trabalho como uma atividade transformadora, consciente, social e ontológica. Para este cientista social é por meio do trabalho que o homem transforma o estado natural dos materiais da natureza para potencializar a sua utilidade, fazendo isso de modo consciente e proposital, ao passo que o trabalho de outros animais é instintivo. Para Braverman o trabalho é fator de continuidade na experiência humana instrumental realizada em diferentes relações e é, também, a atividade pela qual o homem, ao transformar a natureza e agir sobre o mundo externo, modifica a sua própria natureza, conferindo-lhe, assim, uma função ontológica.

O trabalho é, portanto, o fundamento da vida humana, é a atividade de mediação entre o homem e a natureza e resulta como produto do trabalho humano não apenas os objetos e serviços úteis, mas também o Estado, as cidades e as nações. Compreende-se assim o trabalho enquanto atividade consciente e social por meio da qual o homem regula e transforma a natureza em bens necessários à sua sobrevivência e, como resultado deste metabolismo, o homem acaba por construir a si próprio e a estrutura social com seu arcabouço jurídico-político.

A alteração dos meios de trabalho, alterando também as relações entre os homens, muda as condições sociais em que a produção ocorre. $\mathrm{O}$ trabalho cria o homem, potencializa sua força produtiva e lança as bases em que se estabelecem as relações sociais ${ }^{3}$ (RUY, 1997). Para se compreender a sociedade, portanto, sua estrutura social, jurídica e política, é necessário que se volte os olhos para as relações de trabalho, para o modo e os meios com que se realiza a produção material, pois os meios de trabalho não são só medidores do grau de desenvolvimento da força de trabalho humano, mas também indicadores das condições sociais nas quais se trabalha (MARX, 1983, p.151).

\footnotetext{
${ }^{3}$ Em um debate que a Europa como pano de fundo, a chamada centralidade da categoria trabalho, tem sido questionada por um conjunto de teóricos vinculados à Escola de Frankfurt que atribuem à esfera política maior capacidade e força ordenadora da vida social e do Estado, ao invés da esfera produtiva.
} 
Compreendido enquanto atividade vital por meio da qual o homem satisfaz necessidades e se humaniza, o trabalho é, portanto, condição de existência humana, independente do tempo histórico ou das formas de organização e de localização dos grupos sociais.

No entanto, enquanto atividade humana, o trabalho assume formas diferenciadas em função da história ou da geografia dos diferentes grupos humanos. Mesmo sendo atividade de humanização, porque satisfaz as necessidades humanas, no decorrer da história, o trabalho assumiu formas desumanizantes, alienantes ${ }^{4}$, desintegradoras dos valores humanos universais. $\mathrm{Na}$ antiguidade assumiu a forma escravista, na idade média a forma de servidão e na idade moderna assume a forma de trabalho assalariado. Assim, desde a aparição da divisão social do trabalho, esta atividade assume dupla dimensão, atividade de humanização e atividade de alienação. E conforme vão se alterando as formas de realização do trabalho humano se altera também a própria existência humana em um movimento contraditório de humanização/alienação.

Mesmo em diferentes tempos históricos e econômicos, o trabalho vai se metamorfoseando para melhor permitir a produção de excedentes. Um conjunto de transformações desta natureza tem sido verificado na sociedade humana, particularmente a partir das décadas de 1970 e 1980, sendo identificadas como processos de reestruturação da produção capitalista.

As transformações verificadas no mundo da produção são perceptíveis na introdução de novas tecnologias físicas e de novas formas de organização e de gestão do trabalho. As novas tecnologias físicas, baseadas na microeletrônica, e as novas tecnologias de gestão e de organização do trabalho, que buscam o melhor aproveitamento da mãode-obra e a otimização do capital, vêm acarretando modificações radicais na vida das empresas. Ianni afirma que assistimos a passagem do sistema da máquina-ferramenta ao sistema de máquinas auto-reguladas e que isto faz com que o homem, a partir de agora e inversamente aos lugares comuns, deva exercer na automação funções muito mais abstratas, muito mais intelectuais (IANNI, 1994, p. 7). Diminui a importância do trabalho manual

\footnotetext{
${ }^{4}$ Para Masetto (1994), a alienação pode ser compreendida como a contradição entre a
} condição da existência humana e a essência humana. 
repetitivo na produção de riquezas com a automação da produção, de outro lado os empregos que se mantém com a introdução destas novas tecnologias exigem relativamente maior capacidade intelectual dos trabalhadores, assim como novos atributos cognitivos e comportamentais lhe são exigidos como maior capacidade de raciocínio lógico e abstrato, maior responsabilidade e capacidade de cooperação.

Verifica-se assim o relaxamento da divisão técnica do trabalho, parece que diminui a distância entre o fazer e o pensar a produção em função das novas necessidades do capital de buscar novas formas de aumentar a produtividade com novas formas de utilização da mão-de-obra. Em termos práticos isto vem fazendo com que as empresas busquem ter um número reduzido de trabalhadores estáveis, responsáveis pelos setores estratégicos da produção e uma maioria de trabalhadores periféricos que tem a sua utilização definida a partir das necessidades do capital. Junto com esse movimento de terceirização nas empresas, ganha força o setor terciário da economia e esse crescimento vai dar argumentos para, em Offe (1989) e Habermas (1987) por exemplo, o possível surgimento de uma nova lógica social não mais normatizada pela mundo da produção.

Estas modificações, verificadas primeiramente nos países economicamente mais fortes da Europa e da América do Norte e que se colocam como tendência mundial, impõem uma nova divisão internacional do trabalho com a globalização da economia capitalista e também das condições de realização do trabalho. Sobre isso Ianni afirma que: agora, o mundo do trabalho está decisivamente influenciado pelo jogo das forças produtivas e relações de produção em atividade no âmbito do capitalismo como um modo de produção propriamente global (IANNI, 1994, p. 4).

Apesar de serem compreendidas enquanto tendências do mundo do trabalho e que, portanto, de algum modo deve impactar toda a sociedade em seus diferentes grupos sociais inclusive sobre as suas qualificações, exigindo mesmo a constituição de um novo tipo humano ${ }^{5}$ não se pode deixar de reconhecer que esta "revolução tecnológica" chega diferentemente nas várias regiões do planeta, revelando as mediações históricas, geográficas, políticas e culturais que dão contornos específicos para cada espaço geopolítico.

${ }^{5}$ Do mesmo modo que o taylorismo-fordismo construiu um tipo de cultura adequado ao seu tempo o qual Gramsci denominou de americanismo. 
$\mathrm{Na}$ Amazônia, em função das suas muitas peculiaridades, ainda não estão dados os contornos definitivos da sua forma de inserção nesta nova situação de realização do trabalho. De qualquer modo, devem-se buscar formas de ingresso diferentes das historicamente construídas nos diferentes ciclos econômicos aqui predominantes, mascados pelo uso predatório das forças de trabalho e do meio ambiente.

\section{O trabalho na Amazônia ${ }^{6}$}

O trabalho na Amazônia tem se caracterizado por uma forma predatória de realização. Contrastando com a sua riqueza natural, a população amazônica consta nas estatísticas oficiais com as mais baixas expectativas de vida, com os municípios de menor IDH - Índice de Desenvolvimento Humano -, menor renda per capta, com graves problemas ambientais e muitos conflitos agrários que, por vezes, acabam em morte de trabalhadores e de suas lideranças.

A realização do trabalho na Amazônia se dá em um ambiente de muitos contrastes, pois convivem ilhas de modernidade ao lado de formas muito atrasadas de realização do trabalho, a tecnologia de ponta utilizada em empresas organizadas sob a égide do toyotismo convive com o extrativismo e com formas naturais de realização do trabalho. Junto de poderosas companhias que se utilizam das mais modernas tecnologias de gestão do trabalho, bem como de equipamentos de base microeletrônica, persistem comunidades quilombolas, ribeirinhas e indígenas que ainda concretizam formas tradicionais de realização do trabalho.

É na Amazônia também que, ao lado da expansão da moderna agro-indústria, sobrevive o trabalho escravo contemporâneo ${ }^{7}$. A CPT (Comissão Pastoral da Terra) e a OIT (Organização Internacional do Trabalho) estimavam haver em 2007 cerca de 25 mil trabalhadores escravos no Brasil estando metade deles no estado do Pará.

\footnotetext{
${ }^{6}$ Esta seção tem como base o artigo "Amazônia, trabalho escravo, conflitos de terra e reforma agrária" (ARAUJO; GOMES, 1987).

${ }^{7}$ Não há convergência sobre a possibilidade de se usar a expressão "trabalho escravo", já que a situação atual apresenta diferenças com o trabalho escravo clássico, mas, além de algumas regularidades permitir o uso desta expressão, a OIT reconhece o uso desta expressão no Brasil para designar uma forma de trabalho forçado e o Governo Lula a utilizou oficialmente quando lançou o Plano Nacional pela Erradicação do Trabalho Escravo, em 2003.
} 
Também é neste estado que se concentram vários conflitos em torno da posse de terras. Esta situação de trabalho escravo e de conflitos pela terra pode ser visualizada no quadro abaixo:

\begin{tabular}{|c|c|c|c|c|c|}
\hline Ano & $\begin{array}{c}\text { Assassi- } \\
\text { natos }\end{array}$ & $\begin{array}{c}\text { Tentativas } \\
\text { de assassi- } \\
\text { natos }\end{array}$ & $\begin{array}{c}\text { Ameaças } \\
\text { de } \\
\text { morte }\end{array}$ & $\begin{array}{l}\text { Denúncias } \\
\text { de trabalho escravo }\end{array}$ & $\begin{array}{c}\text { Trabalha- } \\
\text { dores } \\
\text { escravos } \\
\text { libertados }\end{array}$ \\
\hline 2000 & 5 & 2 & 17 & 16 casos & 291 \\
\hline 2201 & 8 & 3 & 46 & 24 casos & 1.294 \\
\hline 2202 & 20 & 8 & 78 & 116 casos & 4.227 \\
\hline 2203 & 33 & 21 & 53 & 3.923 trabalhadores & 1.870 \\
\hline 2204 & 15 & 22 & 103 & 2.476 trabalhadores & 1.043 \\
\hline 2205 & 16 & 16 & 96 & 3.198 trabalhadores & 1.266 \\
\hline 2006 & 24 & 8 & 118 & 2.899 trabalhadores & 1.180 \\
\hline Total & $121^{8}$ & 80 & 511 & 12.496 trabalhadores ${ }^{9}$ & 11.171 \\
\hline
\end{tabular}

Fonte: Cadernos de Conflito da Comissão Pastoral da Terra. 2007.

Particularmente em relação ao trabalho escravo, destacamos os dados que revelam a atuação de fiscalização do Estado brasileiro, por meio de grupos de fiscalização do Ministério do Trabalho e Emprego e da Delegacia Regional do Trabalho:

\section{OPERAÇÕES DO GRUPO DE FISCALIZAÇÃO MÓVEL NO ESTADO} DO PARÁ (2000-2006)

\begin{tabular}{|c|c|c|c|c|c|}
\hline Ano & $\begin{array}{c}\mathbf{N}^{\mathbf{o}} \text { de } \\
\text { Operações }\end{array}$ & $\begin{array}{c}\mathbf{N}^{\mathbf{o}} \text { de } \\
\text { fazendas } \\
\text { fiscalizadas }\end{array}$ & $\begin{array}{c}\text { Trabalha- } \\
\text { dores } \\
\text { libertados }\end{array}$ & $\begin{array}{c}\text { Valor } \\
\text { médio das } \\
\text { indenizações } \\
\text { por número de } \\
\text { trabalhadores } \\
\text { libertados }\end{array}$ & $\begin{array}{c}\text { Valor } \\
\text { médio das } \\
\text { indenizações } \\
\text { por fazendas } \\
\text { fiscalizadas }\end{array}$ \\
\hline 2000 & 05 & 9 & 265 & 796,20 & $23.443,29$ \\
\hline 2001 & 10 & 16 & 527 & 546,40 & $17.997,19$ \\
\hline 2002 & 12 & 42 & 1.392 & 849,50 & $28.154,64$ \\
\hline 2003 & 29 & 105 & 1.888 & $1.535,60$ & $27.611,20$ \\
\hline 2004 & 23 & 47 & 908 & $1.874,60$ & $36.215,10$ \\
\hline 2005 & 24 & 65 & 1.205 & $1.918,50$ & $35.566,01$ \\
\hline 2006 & 31 & 53 & 1.062 & $1.794,70$ & $35.960,86$ \\
\hline Total & $\mathbf{1 3 4}$ & $\mathbf{3 3 7}$ & $\mathbf{7 . 2 4 7}$ & $\mathbf{1 . 4 4 8 , 9 3}$ & $\mathbf{3 1 . 1 5 8 , 5 8}$ \\
\hline
\end{tabular}

Fonte: SEINT DRT-PA

\footnotetext{
${ }^{8}$ Esse número representa $43 \%$ do total de trabalhadores rurais assassinados no Brasil.

${ }^{9}$ Esse número representa $45 \%$ do total de trabalhadores resgatados no Brasil.
} 
Os conflitos em torno da posse da terra estão relacionados com uma forma de ocupação do campo na Amazônia em que prevalece o latifúndio e são resultado, também, da ausência das políticas públicas do Estado no interior desta região capazes de regular as relação de trabalho, assegurar o acesso a terra e o fomento da produção nas pequenas propriedades e de conter a força política e o braço armado do latifúndio.

A zona rural amazônica, e particularmente a paraense, fora ocupada sempre privilegiando o latifúndio. Já em meados do século XIX o ciclo da borracha, que foi o primeiro fluxo migratório importante para a região, tem como marcas o privilégio da grande propriedade e a constituição de sistema de aviamento.

Desde 1844, nordestinos, principalmente do Ceará, vieram ocupar áreas da Amazônia, formando a primeira leva dos chamados "soldados" da borracha. Mais tarde, em 1877, uma outra seca no Nordeste impulsionou mais um movimento de pessoas rumo aos seringais. A época da borracha foi tida como um período "dourado" para a Amazônia e criouse, assim, uma elite que estabeleceu um sistema de aviamento e, a seu modo, marcaria as relações sócioeconômicas na região. Este empreendimento sofreu uma queda brusca a partir de 1910. (FORLINE, 2007).

É este sistema de aviamento, que tem origem há mais de 150 anos, que vai se manter e favorecer o trabalho escravo contemporâneo que se consolida sobre as dívidas impagáveis do trabalhador.

Outro ciclo importante se deu a partir da década de 1960, com a implementação dos grandes projetos na Amazônia, sob a marca da doutrina de segurança nacional que via a integração da Amazônia ao Brasil como uma resposta às ameaças à soberania nacional. A partir daí programaram-se projetos de abertura de estradas e de grandes projetos.

A era dos Grandes Projetos na Amazônia esboçou uma nova face para a região. No período do Milagre Econômico Brasileiro, nos anos 1970, o governo federal implementou seu Projeto de Integração 
Nacional (PIN), badalando o mesmo como uma oportunidade de oferecer "terras sem homens para homens sem terra". Criou-se, então, uma malha rodoviária e novos projetos agrícolas para assentar povos de lugares distantes. $\mathrm{Na}$ ocasião, o governo militar objetivava ocupar a Amazônia, com o intuito de solidificar sua soberania e escoar pessoas de outras regióes potencialmente conflituosas (FORLINE, 2007)

Os grandes projetos tiveram pouco impacto no desenvolvimento da região, mas provocaram o acirramento dos problemas sociais e demográficos. Quem mais lucrou foram as empreiteiras e parte das elites locais que conseguiram ter acesso a parte dos recursos destinados à implementação da política de integração da Amazônia. Também lucraram os grileiros que se apropriaram de grandes extensões de terras.

Tanto o ciclo da borracha quanto o dos grandes projetos revelaram um tipo de ocupação das vastas extensões das terras amazônicas em que se privilegiou o latifúndio em detrimento das pequenas propriedades e o uso predatório da força de trabalho e da natureza.

Colabora com a permanência dos conflitos agrários a não garantia dos direitos dos trabalhadores e a pouca presença do Estado na zona rural da Amazônia. Isto pode ser evidenciado no fenômeno da reincidência de propriedades rurais que fazem uso de mão-de-obra escrava e no perfil do trabalhador escravo. A reincidência e o perfil do trabalhador escravo revelam não apenas e ausência do Estado como garantidor das condições dignas de sobrevivência humana, mostra também a face mais cruel de realização do trabalho rural na Amazônia. Coloca-se, assim, como marca do trabalho no campo amazônico o uso predatório da força de trabalho, que não respeita direitos e se sustenta na ausência do Estado e na força do latifúndio.

Também caracteriza a realização do trabalho na Amazônia o uso predatório da natureza. Sobre isso, Vera de Almeida e Val, pesquisadora do INPA - Instituto Nacional de Pesquisa da Amazônia -, afirma que a exploração dos recursos naturais (biológicos ou não) tem atingido o meio ambiente como um punhal que se crava lentamente (VAL, 2007). Para ela, não são trabalhadores individuais que, em busca de riqueza, dilapidam o patrimônio genético da Amazônia, mas empresas consolidadas, nacionais 
e multinacionais que exploram madeira, minérios e agora petróleo. Estas deixam como saldo a desertificação e a erosão.

Esta mesma pesquisadora faz um alerta de que, no atual momento, nos deparamos com o fantasma da exploração da biodiversidade, que, como "apenas" detentora de material genético, esconde em si riquezas insondadas, que, se indevidamente exploradas, poderão se esgotar antes mesmo que saibamos seu valor (VAL, 2007).

Assim, observamos que os modelos de desenvolvimento até agora adotados na região privilegiam a reprodução do capital em detrimento do homem e da natureza, assim projetos como os das grandes mineradoras têm sido muito eficientes nos processos de reprodução do capital, favorecendo seus acionistas ${ }^{10}$, em detrimento dos trabalhadores das regiões onde estão instaladas as suas unidades ou da preservação do meio ambiente.

\section{Por um novo modelo de desenvolvimento referenciado no homem}

A tendência atual de expansão da agro-indústria, organizada em grandes extensões de terra, revelam a continuidade de uma cultura instituída de exploração da terra em que se privilegia o latifúndio em detrimento das pequenas propriedades.

Um novo modelo de desenvolvimento da Amazônia é necessário e este requer:

a) Uma inversão de valores. O trabalhador, particularmente os trabalhadores rurais e os pequenos proprietários, os indígenas, ribeirinhos e as populações tradicionais, devem se constituir no principal balizamento para os projetos de desenvolvimento regional que se propõem qualitativamente diferentes. $\mathrm{O}$ homem é a principal referência e em seu benefício devem ser organizados os planos de desenvolvimento econômico e social.

\footnotetext{
${ }^{10}$ A Vale obteve o lucro recorde de aproximadamente 12,5 bilhões de dólares em 2006. cf. http://www.cvrd.com.br/cvrd/media/factsheetp.pdf
} 
b) A Reforma agrária como bandeira de luta que interessa aos trabalhadores rurais e aos pequenos proprietários. Será por meio de estratégias de redistribuição de terras e de assistência e de fomento à produção que se poderão construir condições de trabalho em que seja valorizado o homem Amazônida.

c) Um novo modelo de desenvolvimento construído de modo a articular a promoção do homem, o desenvolvimento econômico, o conhecimento científico, a sustentabilidade ambiental e a valorização das riquezas regionais.

Para tanto, o conhecimento torna-se cada vez mais estratégico, pois ainda se caracteriza como um ponto frágil da nossa soberania. Fossem nossos ecossistemas mais bem conhecidos e melhor assistidos científica e tecnologicamente, nosso debate seria enriquecido e seguramente teríamos "defesa". (VAL, 2007).

Este modelo de desenvolvimento deve ser viabilizado como resultado de um processo de diálogo entre os diferentes setores da sociedade regional, em especial de um diálogo franco entre Estado, setores produtivos (inclusive pequenos produtores), instituições de ciência e tecnologia e as organizações dos trabalhadores. O desenvolvimento, nesta perspectiva, não pode resultar de um planejamento feito de fora para dentro, como tem prevalecido historicamente, mas deve partir daquilo que interessa aos trabalhadores da Amazônia.

Do mesmo modo, qualquer projeto de universidade da Amazônia deve pressupor uma relação com o mundo produtivo que também se oriente sob a ideia da necessidade de valorização do homem da Amazônia. Nesta direção deve-se considerar que qualquer projeto de desenvolvimento econômico-social não pode prescindir de estratégias educacionais que lhe corresponda e lhe dê suporte. Mas são várias as compreensões acerca da relação entre a esfera educativa e a esfera da produção e que merecem ser objeto de avaliação política por aqueles que definem os rumos da educação e da ciência nesta região. 


\section{Diferentes formas de compreender a relação entre trabalho e educação e a universidade}

Educação etimologicamente significa educare (conduzir). Pode ser compreendida como processo de formação (condução) do homem. Poderíamos afirmar que educação, do verbo educar, significa "trazer à luz a ideia" ou filosoficamente fazer a criança passar da potência ao ato, da virtualidade à realidade (MARTINS, 2009). Na antiguidade os processos educacionais não se distinguiam dos processos de trabalho, mas, ainda na Grécia antiga, surgem os espaços reservados especificamente para a educação, a escola (etimologicamente lugar do ócio).

As relações que se estabelecem (ou não se estabelecem) entre estes dois termos, entre os processos de produção da vida material e os processos de formação humana, constituem objeto de muitas pesquisas, debates e controvérsias. No Brasil a relação de trabalho e educação constitui uma área definida de pesquisa ${ }^{11}$, uma subárea da educação.

Neste campo, as teorias não se somam, se embatem, sob diferentes perspectivas que podem ser assim compreendidas:

- Adeptos da Escola de Frankfurt (no Brasil com forte influência dos alemães Juergen Habermas e Claus Offe): Estes abandonam a ideia de classe social e da centralidade do trabalho e reclamam uma situação autônoma dos processos educacionais frente ao "mundo do trabalho".

- Pós-modernistas: Se voltam para a análise do sujeito na sua cotidianidade e descolam-no, porém, dos processos de construção da sua vida material.

- Neoliberais: Buscam naturalizar e legitimar as desigualdades sociais existentes e, sob a ideia da "mão invisível" do mercado como reguladora da vida social, propõem um modeloeducacional subordinado aos interesses imediatos e fragmentados das empresas, do capital. Buscam responsabilizar o trabalhador por

${ }^{11}$ Sobre a produção em Trabalho e Educação recomendo TREIN e CIAVATTA (2004). 
seu emprego e desemprego. Sob esta perspectiva defende-se a ideia de uma "universidade operacional" (CHAUÍ, 1999).

- Marxistas (de diferentes matizes): Defendem a integração entre trabalho e educação por meio da superação da divisão da sociedade de classes e, de imediato, da resistência aos processos de embrutecimento do trabalhador e da defesa de uma escola unitária, que promova a integração entre as capacidades de pensar e de fazer de todos os trabalhadores.

São quatro posições conflitantes que determinam a forma de se compreender os processos educacionais e tudo que a ele está relacionado, tal como os processos de formação de professores. É sob a perspectiva da integração, fundada na Filosofia da Práxis, que estamos aqui tecendo as nossas considerações.

Compreende-se aqui que a relação entre trabalho e educação é indissolúvel, pois os processos de formação da subjetividade humana estão diretamente relacionados à objetividade de sua existência. Não se pode desvencilhar a atividade de transformação do mundo do processo de formação do ser.

Saviani, sobre essa relação, observa que:

O homem não nasce homem. Ele se forma homem. Ele não nasce sabendo produzir-se como homem. Ele necessita aprender a ser homem, precisa aprender a produzir sua própria existência. Portanto, a produção do homem é, ao mesmo tempo, a formação do homem, isto é, um processo educativo. A origem da educação coincide, então, com a origem do homem mesmo (SAVIANI, 2006, p. 4).

A separação da dimensão produtiva do homem da sua dimensão formativa, de "trazer à luz", tem origem na divisão social e técnica do trabalho. Tomar esta separação como natural representa assumir que a alguns cabe a tarefa de produzir e a outros a tarefa de pensar.

O surgimento da sociedade de classes fez surgir ainda no mundo antigo dois tipos de educação, dois processos diferenciados de formação humana. Um, para as elites, orientado para o desenvolvimento de 
capacidades intelectuais, superior e propedêutico, e outro, voltado para os trabalhadores, focado no próprio processo de trabalho, capaz de desenvolver apenas capacidades elementares e instrumentais.

Portanto, não é ao trabalhador que interessa a cristalização desta separação entre trabalho e educação ou entre educação para o trabalho e educação para a governança.

A utopia de uma sociedade do trabalho, dos trabalhadores, exige um modelo formativo que reconheça o trabalho como atividade criadora de bens e serviços, mas, também, criadora do próprio homem. Tratase, pois, de valorizar o trabalho e o trabalhador. Também isto é uma exigência para quem pensa a formação de professores à luz da necessidade de um sistema educativo, incluindo a universidade, que interessa aos trabalhadores.

O horizonte que deve nortear um projeto educacional desta natureza é a de um tipo de educação que assegure o acesso aos fundamentos científicos gerais de todos os processos de produção, fazendo da universidade um ambiente cultural por meio da qual seja possível estabelecer o diálogo, em igualdade de condições, entre a comunidade universitária e a sociedade em geral, em torno dos conhecimentos que são produzidos e socializados e que devem favorecer ao enfrentamento dos diferentes problemas que afetam a todos.

Alguns princípios políticos que devem mover este projeto de universidade podem ser definidos como compromissos com uma sociedade radicalmente democrática, com a ideia de uma educação integral, com os processos de qualificação duradoura dos trabalhadores e com a ampliação permanente das capacidades intelectuais e operativas de todos os cidadãos, em um processo que valorize a ciência, mas, e principalmente, valorize o trabalho humano.

\section{Em busca de considerações conclusivas: a função social da universidade frente ao mundo do trabalho}

Sob esta perspectiva integradora da educação e do trabalho, compreendemos que o princípio unitário pugnado por Gramsci para a escola não incide somente sobre a escola, mas também sobre as relações entre trabalho industrial e trabalho intelectual e diz respeito a toda vida social e a todos os organismos de cultura. 
Do mesmo modo deve ser um princípio orientador das práticas formativas na universidade. Estas, que constantemente vêm sendo acusadas (não sem razão) de serem separadas da vida, sob o princípio da integração poderão assumir novas funções. As academias deverão se tornar a organização cultural de sistematização, experiência e criação intelectual daqueles que após a escola unitária passarão para o trabalho profissional, bem como um terreno de encontro entre estes e os universitários (GRAMSCI, 1991, p. 125).

Assim, pugna-se por uma universidade que não seja o corolário da dualidade educacional brasileira, mas espaço de integração entre trabalho produtivo e trabalho intelectual, conferindo às suas diferentes unidades (centros, faculdades, núcleos e institutos) vinculadas a alguma especialidade da atividade profissional humana, a possibilidade de atuarem contra a passividade intelectual, cumprindo uma função orgânica de iniciativa coletiva.

Sua organização acadêmica deve espelhar esta orientação e internamente deve valorizar o trabalho docente, o trabalho técnico e o estudo como atividade. Do mesmo modo, não apenas para fortalecer um projeto de sociedade democrática, mas para viabilizar o desenvolvimento da capacidade criativa de todos, a universidade deve se organizar de modo democrático, permitindo o livre pensar, o contraditório e a possibilidade de participação ampla da comunidade docente nos processos decisórios.

Assim, a universidade não pode ser compreendida como uma "organização social", mas como uma instituição social. Chauí (1999) estabelece as diferenças entre estes dois modelos de universidade, um que se funda na subordinação da educação ao projeto liberal de "livre mercado", outro que se funda na perspectiva democrática de uma universidade autônoma e criativa.

Uma organização difere de uma instituição por definir-se por uma outra prática social, qual seja, a de sua instrumentalidade: está referida ao conjunto de meios particulares para obtenção de um objetivo particular. [...] Não está referida a ações articuladas às ideias de reconhecimento externo e interno, de legitimidade interna e externa, mas a operações definidas como estratégias balizadas pelas ideias de eficácia e de sucesso no emprego de determinados meios para alcançar o objetivo particular que a define. 
Já a instituição social se percebe inserida na divisão social e política e busca definir uma universalidade (ou imaginária ou desejável) que lhe permita responder as contradições impostas pela divisão.

As relações externas, portanto, que a universidade deve estabelecer, devem também estar orientadas pela necessidade de valorização do homem da Amazônia, na perspectiva de sua emancipação e não de sua subordinação às demandas do sistema ocupacional. Devem ser vivas, portanto, em seus diálogos com outras instituições de ensino e pesquisa da região visando o estabelecimento de uma ampla rede de valorização do trabalho humano, bem como, visando a organização de trabalhadores e da esfera produtiva, tendo em vista a discussão dos problemas reais que afetam a vida do Amazônida.

Deste modo, o mercado não serve como conceito regulador da vida universitária, pois a sua lógica é de natureza diversa da lógica da vontade coletiva, pública. A Universidade não pode ser orientada por critérios como o de produtividade, observada na relação quantidade-tempo-custo, pois seus produtos e serviços têm antes um caráter formativo e devem obedecer ao critério da relevância social.

A força e a legitimidade da universidade em todo o mundo vêm exatamente da independência, mesmo que relativa, que historicamente construiu em relação ao estado, a religião e ao mercado, portanto o progresso da ciência e vínculos fortes com as necessidades humanas devem ser balizas melhor que o mercado para o seu funcionamento, permitindo o resgate das funções históricas do trabalho e da educação: a humanização.

A articulação universidade e empresa pode e deve acontecer, mas orientada pelas necessidades de construção de uma sociedade solidária, democrática, valorizadora do trabalho humano e da natureza.

Deve-se priorizar as instituições públicas, pois estas têm uma constituição diferenciada e representativa dos interesses gerais da sociedade. Deve-se ainda considerar as empresas para que estas possam cumprir funções sociais relevantes no desenvolvimento de serviços e materiais necessários para a melhoria da qualidade de vida dos amazônidas e de toda a humanidade.

Não se pode vincular a universidade a projetos econômicos que prejudiquem a Amazônia, que possam causar danos ao meio ambiente 
ou que façam uso predatório das forças de trabalho (trabalho escravo, trabalho infantil e outras formas de atividades laborais que degradem a vida e o meio ambiente), mesmo que indiretamente. Isso seria um grande desserviço ao desenvolvimento social desta região.

O objetivo da universidade não é gerar lucro (maisvalia), mas contribuir para a melhoria da qualidade de vida, ou seja, produzir a humanização, e este princípio deve orientar a aproximação desta instituição de ensino, pesquisa e extensão com organizações empresariais, públicas e privadas. Assim a universidade pode cumprir a sua função social de humanização.

\section{REFERÊNCIAS}

ARAUJO, Ronaldo Lima; GOMES, Socorro. Amazônia: trabalho escravo, conflitos de terra e reforma agrária. Revista Princípios. n, 87, São Paulo, 2007. pp. 26-29.

BRAVERMAN, Harry. Trabalho e Força de Trabalho. In: Trabalho e Capital Monopolista. Rio de Janeiro. Editora Guanabara, 1974. pp. 4960.

CHAUÍ, Marilena. A Universidade Operacional. In: Folha de São Paulo/Caderno Mais. 09/05/1999. São Paulo, 1999.

CPT. Conflitos no Campo no Brasil. Goiânia: CPT, 2007.

FORLINE, Louis. As Várias Faces da Amazônia: Migrações, Deslocamentos e Mobilidade Social na Região Norte. Disponível em:

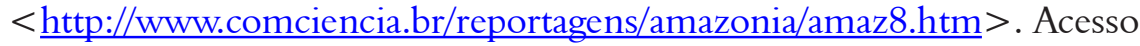
em: 12/06/2007.

GRAMSCI, Antonio. Organização da escola e da cultura. In: Os intelectuais e a organização da cultura. São Paulo: Cortez, 1991. pp. 117129.

HABERMAS, Jurgen. A nova intransparência: a crise do Estado do Bem estar e o esgotamento das energias utópicas. Novos Estudos CEBRAP, n. 18, São Paulo, 1987. 
IANNI, Otávio. O Mundo do Trabalho. Revista São Paulo em Perspectiva. São Paulo, SEADE, 1994.

MARTINS, Evandro Silva. A Etimologia de Alguns Vocábulos Referentes à Educação. http://www.seer.ufu.br/index.php/ olharesetrilhas/article/viewFile/182/183. Acesso em: 08/05/2009.

MARX, Karl, O Capital. livro 1, tomo 1. São Paulo: Abril Cultural, 1983. Coleção os Economistas.

MASETTO, Marcos. Didática: aula como centro. São Paulo: FTD, 1994.

OFFE, Claus. Trabalho: a categoria-chave da sociologia? In: Revista Brasileira de Ciências Sociais. v. 4, n. 10, Rio de Janeiro, 1989. pp. 5-20.

RUY, José Carlos. O operário faz a coisa e a coisa faz o operário. Revista Princípios. n. 43, nov/96-jan/97, São Paulo: Ed. Anita Garibaldi, 1997.

SAVIANI, Dermeval. Trabalho e Educação: Fundamentos Ontológicos e Históricos. Trabalho encomendado pelo GT - Trabalho e Educação, apresentado na 29 $\mathbf{2}^{\mathbf{a}}$ Reunião da ANPEd no dia 17 de outubro de 2006. Caxambu, 2006.

TREIN, Eunice; CIAVATTA, Maria. O percurso teórico e empírico do GT Trabalho e Educação: Uma Análise para debate. In: ANPED/Revista Brasileira de Educação. Rio de Janeiro: autores associados. n. 24, Out/ nov/dez, 2004.

VAL, Vera Maria Fonseca de Almeida. A Amazônia, a biodiversidade e o novo milênio. www.comciencia.br. Acesso em 05/06/2007.

Vale do Rio Doce. http://www.cvrd.com.br/cvrd/media/factsheetp.pdf. Acesso em 08/06/2007. 